\title{
PLURILINGUISMOS INDÍGENAS NO MUNDO GLOBALIZADO ${ }^{1}$
}

\section{INDIGENOUS PLURILINGUALISMS IN THE GLOBALIZED WORLD}

\author{
André Marques do Nascimento ${ }^{2}$
}

\begin{abstract}
RESUMO: Neste trabalho, argumento que a invisibilização epistemológica de práticas comunicativas indígenas na modernidade recente é resultante de estratégias coloniais da "invenção de línguas" fundada em prefigurações identitárias etnolinguísticas. Tais invenções se mostram limitadas para a compreensão da dinamicidade intercultural de povos $e$ indivíduos indígenas e da mobilidade impulsionada pelos processos recentes de globalização. Ilustro como o uso de tecnologias móveis de comunicação tem se tornado um canal produtivo para usos híbridos de recursos semióticos que, por um lado, desestabiliza ideologias monolíngues e prefigurações identitárias e, por outro, se mostra como um potencial meio para a vitalidade das chamadas línguas indígenas. Utilizo, para esta análise, a noção de práticas transidiomáticas, mas apresento críticas quanto ao seu escopo geopolítico. Aponto, finalmente, para a pertinência da categoria tetsualü para a análise de dinâmicas interculturais e de práticas comunicativas híbridas pensadas, por sua vez, desde o espaço da diferença colonial.
\end{abstract}

PALAVRAS-CHAVE: Plurilinguismo Indígena; Globalização; Práticas Transidiomáticas; Tetsualü.

ABSTRACT: In this work, I argue that the epistemological invisibilization of indigenous communicative practices in late modernity is a result of colonial strategies of "invention of languages" based on ethnolinguistic identity prefigurations. Such inventions are limited in understanding the intercultural dynamicity of indigenous peoples and individuals, as well as their mobility driven by the recent processes of globalization. In this way, I seek to illustrate how the use of mobile communication technologies has become a productive channel for hybrid uses of semiotic resources that, on the one hand, destabilizes monolingual ideologies and identity prefigurations and, on the other hand, shows itself as a potential medium for the vitality of so-called indigenous languages. I use, for this analysis, the notion of transdiomatic practices, instead I present some criticism concerning its geopolitical scope. Finally, I briefly point out the pertinence of the indigenous category "tetsualü" for the analysis of intercultural dynamics and hybrid communicative practices, thought, in its turn, from the space of colonial difference.

KEYWORDS: Indigenous Plurilingualism; Globalization; Transidiomatic Practices; Tetsualü.

\footnotetext{
${ }^{1}$ Este trabalho é resultante das reflexões desenvolvidas no âmbito do projeto de pesquisa "Alternativas situadas para descolonização de práticas, ideologias e regimes de linguagem em contextos pós-coloniais interculturais", por mim coordenado. Agradeço imensamente a um/a dos/as pareceristas anônimos/as deste trabalho pelos comentários e sugestões absolutamente críticos e pertinentes, que colaboraram sobremaneira para a precisão conceitual e teórico-analítica das reflexões aqui apresentadas. As limitações que nele permanecem são, naturalmente, de minha responsabilidade.

${ }^{2}$ Doutor em Letras e Linguística pela Universidade Federal de Goiás. Professor Adjunto do curso de Educação Intercultural e do Programa de Pós-Graduação em Linguística da UFG.
} 


\title{
Introdução
}

Viveiros de Castro, ao prefaciar a importante obra A queda do Céu: palavras de um xamã yanomami, reconhece o valor epistemológico do pensamento do importante líder indígena Davi Kopenawa como "um acontecimento científico incontestável” (VIVEIROS DE CASTRO, 2015, p. 15), vivenciado e elaborado desde a experiência geo e corpo-política (MIGNOLO, 2011) de quem vive, pensa e sente no espaço da diferença colonial e sofre, historicamente, as consequências mais diretas da colonização. Ao introduzir a obra ao público brasileiro, Viveiros de Castro faz uma crítica contundente sobre a relação entre indígenas e não indígenas no que diz respeito especialmente à geopolítica do conhecimento e à reificação de corpos e epistemologias subalternizados e constata que

\begin{abstract}
[r]ecusar aos índios uma interlocução estética e filosófica radicalmente 'horizontal' com nossa sociedade, relegando-os ao papel de objetos de um assistencialismo terceirizado, de clientes de um ativismo branco esclarecido, ou de vítimas de um denuncismo desesperado, é recusar a eles sua contemporaneidade absoluta. Nosso tempo é o tempo do outro, para glosarmos, e invertermos, a bandeira que Johannes Fabian agitava em 1983. Pois os tempos são outros. E o outro, mais ainda. (VIVEIROS DE CASTRO, 2015, p. 34, ênfase no original)
\end{abstract}

A ideia de negação da contemporaneidade indígena, explícita na crítica do antropólogo brasileiro, é aqui fundamental para o desenvolvimento de meus argumentos. De maneira geral, conforme elabora Mignolo (2010), trata-se de um construto ideológico, parte de uma grande e potente meta-narrativa, que constrói performaticamente a modernidade desde a perspectiva eurocentrada, e que tem como uma das maiores e mais duradouras consequências o posicionamento dos povos colonizados no passado em relação à experiência europeia, instituindo sua existência racialmente hierarquizada como primitiva, atrasada e subdesenvolvida em relação ao homem europeu e, assim, tornando-os "objetos fora da Europa e [portanto] fora da modernidade" (MIGNOLO, 2010, p. 64) ${ }^{3}$. Na arena da geopolítica do conhecimento, a consequência mais nítida e ainda atuante é a instituição das epistemologias não europeias como presas ao momento anterior à marcha triunfal da modernidade em direção ao apogeu do desenvolvimento da humanidade e, por isso, válidas apenas na ordem do mito, da lenda, do folclore, do conhecimento local e tradicional (MIGNOLO, 2011, p. 80).

\footnotetext{
${ }^{3}$ Todas as traduções de citações são de minha inteira responsabilidade.
} 
No que se segue, busco, desde essas assunções sócio-históricas de amplo escopo, tecer reflexões críticas sobre como os efeitos da instituição da modernidade e de seu lado obscuro, a colonialidade, continuam atuantes na produção hegemônica de conhecimento no mundo moderno/colonial, com especial ênfase nos estudos que se dedicam à compreensão de práticas plurilíngues impactadas por processos de globalização. Meu argumento principal é de que a contemporaneidade indígena, e as práticas comunicativas híbridas, móveis e tecnologicamente mediadas que a constitui, continuam sendo negadas, ou invisibilizadas, na produção de conhecimentos sobre linguagem, inclusive em vertentes mais críticas à racionalidade moderna, principalmente por manterem seu posicionamento geo e corpo-político e, portanto, epistemológico, nos centros da modernidade.

Assim, nas seções seguintes, respectivamente, argumento que a invisibilização de práticas comunicativas indígenas na contemporaneidade é resultante e perpetuadora de estratégias coloniais de invenção de "línguas" (MAKONI \& PENNYCOOK, 2007), que se fundam em prefigurações identitárias de cunho etnolinguístico, limitadas para a compreensão da dinamicidade intercultural de povos e indivíduos indígenas e da mobilidade impulsionada pelos processos recentes de globalização, que inevitavelmente também os afeta. Na sequência, ilustro como o uso de tecnologias móveis de comunicação tem se tornado um canal produtivo para usos híbridos de recursos semióticos que, por um lado, desestabiliza ideologias monolíngues e prefigurações identitárias e, por outro, se mostra como um potencial meio para a vitalidade das chamadas línguas indígenas. Utilizo, para esta análise, a noção de práticas transidiomáticas (JACQUEMET, 2005, 2016a), mas apresento críticas quanto ao seu escopo geopolítico. Aponto, finalmente, para a pertinência de uma categoria de análise de dinâmicas interculturais e de práticas comunicativas híbridas, tetsualü (MEHINAKU, 2010), pensada, por sua vez, desde o espaço da diferença colonial.

\section{Práticas comunicativas indígenas: invenção, reificação e invisibilidade}

Para a compreensão do que chamo aqui de invisibilização de práticas comunicativas indígenas contemporâneas, afilio-me, de maneira mais ampla, à perspectiva crítica proposta por Makoni e Pennycook (2007, p. 01), segundo a qual "línguas, concepções de linguacidade [languageness] e as metalinguagens usadas para descrevê-las são invenções [...], particularmente como parte de projetos cristãos/coloniais e nacionalistas", como uma importante estratégia de governabilidade de corpos e práticas sociais nos territórios colonizados. 
Através de processos sociais e semióticos altamente influenciados por ideologias raciais, agentes colonizadores (missionários, administradores, funcionários coloniais, etnólogos etc.) se empenharam em identificar, delimitar, mapear e descrever práticas comunicativas dos povos colonizados. Como resultado, forjaram performaticamente, desde sua própria percepção e, muitas vezes, desde uma compreensão linguística parcial e limitada, a existência de entidades discretas, autônomas, descontextualizadas, nomeáveis e enumeráveis, i.e. as "línguas", como o português, o espanhol, o guarani etc., transformando-as em objetos de conhecimento europeu, dimensão fundamental do controle e da vigilância dos territórios e povos colonizados. Neste processo, os territórios coloniais eram como tábulas rasas, nas quais "os europeus tiveram de mapear suas categorias. As categorias que foram criadas incluíam nomes de grupos étnicos, línguas e como tinham de ser descritas” (MAKONI \& PENNYCOOK, 2007, p. 7).

A ideia de "línguas" como entidades inventadas não significa, naturalmente, que nos territórios colonizados os diferentes grupos não se comunicavam linguisticamente. A crítica recai sobre a imposição de uma categoria sociocultural e política exógena que, ao mesmo tempo em que dava existência a entidades discretas e bem delimitadas, nomeando-as, instituíam também identidades étnicas e raciais não menos fixas e territorializadas, com base nas partes de discursos descontextualizadas que passaram a representar "a língua" daquele grupo. Obviamente, tais processos envolveram relações altamente hierarquizadas de poder e, para se concretizarem, necessitaram da criação de instrumentos metalinguísticos que os legitimassem e produzissem "efeitos de língua", ou seja, sua materialização através de discursos e metadiscursos que, alegadamente, apenas os descreviam (PENNYCOOK, 2007). Torna-se bastante compreensível, então, que uma das principais tarefas de agentes colonizadores nos territórios dominados tenha sido a ostensiva produção de gramáticas, dicionários, lista de palavras e, consequentemente, a instituição de padrões de escrita para as "línguas" dos grupos colonizados, visando sua regulação. Muito embora Makoni e Pennycook situem sua crítica epistemológica com mais ênfase no espaço geopolítico africano, cujos processos de colonização deram-se na chamada segunda modernidade, parece inequívoca a similaridade com processos ocorridos séculos antes, na colonização do que veio a se chamar América, bem como sua perpetuação até a contemporaneidade.

Em território brasileiro, é notável, por exemplo, como missionários cristãos se devotaram à compreensão de línguas indígenas como meio para operacionalizar a conversão das populações nativas ao cristianismo e, como fim último, à Coroa Portuguesa. Imbuídos por uma teopolítica do conhecimento (MIGNOLO, 2010), esta apropriação se deu em diferentes 
níveis e se materializou em instrumentos metadiscursivos, como manuais, gramáticas, vocabulários, entre outros. A Arte de Gramática da Língua mais usada na Costa do Brasil (1595), atribuída ao jesuíta José de Anchieta, é um dos primeiros resultados desta estratégia colonial. Elaborada com base em categorias gramaticais e estruturas do latim, a Arte do jesuíta exerceu importante papel na delimitação do tupi, de sua redução à escrita e na instituição da identidade etnolinguística de seus falantes (cf. SOUZA, 2007). Torna-se ainda mais importante reconhecer que tais processos foram continuamente reiterados no Brasil, em diferentes épocas e com diferentes grupos indígenas, tendo sido mesmo apropriados e implementados como política linguística estatal, amparada pelo discurso científico, como é exemplar o caso da associação entre o Summer Institute of Linguistics (SIL), o Estado brasileiro e importantes universidades, em meados do século XX (cf. BARROS, 1994; 2004). Como legado das ideologias e práticas coloniais, i.e. a colonialidade contemporânea, percebese como a presença missionária continua forte entre populações indígenas e como a invenção de línguas continua atuante, especialmente através de sua redução às formas escritas para tradução da bíblia ${ }^{4}$.

Embora não partam de uma visão materialista de língua, Makoni e Pennycook reconhecem que sua invenção, assim como de conceitos correlatos (língua materna, bilinguismo, code-switching etc.), tem efeitos materiais reais nas vidas dos falantes, particularmente insidiosos para as populações indígenas, uma vez que a própria invenção do construto "povos indígenas", que inclui, necessariamente, as "línguas indígenas", é comprada a um alto preço social, pois "ela fixa suas identidades, consequentemente desqualificando povos indígenas urbanizados" (MAKONI \& PENNYCOOK, 2007, p. 23), assim como qualquer grupo que, de alguma forma, apresente diferentes dinâmicas e arranjos entre cultura, língua e territórios, como no caso de grupos que utilizam prioritariamente, e por diferentes razões, a língua portuguesa em detrimento das línguas indígenas.

No Brasil, são exemplares discursos propagados pela mídia hegemônica que desqualificam comunidades e indivíduos indígenas que não se enquadram em prefigurações essencializadas de indianidade. Tais discursos se alinham, explicitamente, aos interesses econômicos e desenvolvimentistas, que, por sua vez, retomam e implementam discursos e práticas coloniais, para os quais as terras indígenas são, historicamente, um empecilho para o progresso e para o desenvolvimento.

\footnotetext{
${ }^{4}$ Para exemplo da implementação contemporânea da teopolítica do conhecimento e de sua abrangência entre os povos indígenas brasileiros, remeto o leitor e a leitora à página virtual da Missão Novas Tribos do Brasil: http://www.novastribosdobrasil.org.br/tribos-2/demonstrativo-linguistico-e-de-traducao-biblical, acesso em maio de 2017.
} 
Notório, neste sentido, é o caso da pesquisa encomendada, em 2012, ao Instituto de Pesquisas DataFolha pela Confederação da Agricultura e Pecuária do Brasil (CNA) sobre o "perfil dos índios brasileiros", repercutida na imprensa brasileira exatamente por seus resultados ampararem, sob a legitimidade da pesquisa científica, a tese de que os índios não vivem mais conforme modos "tradicionais", apesar de demandarem a posse de seus territórios "tradicionalmente ocupados". Ao apresentar os resultados dessa pesquisa, o jornal Folha de São Paulo ${ }^{5}$, por exemplo, alinha discursos de integração à vida urbana: “os índios brasileiros estão integrados ao modo de vida urbano. Televisão, DVD, geladeira, fogão a gás e celulares são bens de consumo que já foram incorporados à rotina de muitas aldeias", com aspectos de seu repertório comunicativo: "a maioria dos índios (66\%) sabe ler, e 65\% sabem escrever na língua portuguesa".

A fórmula para a compreensão dos efeitos destes discursos midiáticos parece simples: a autenticidade cultural, nela incluída uma identidade etnolinguística fixa, é o que, em tese, garantiria aos povos indígenas certos direitos, como o de terem legalmente reconhecidos os seus territórios tradicionais. O discurso de autenticidade, ou inautenticidade, é, contudo, apropriado contingencialmente, a depender dos interesses político-econômicos supralocais, a despeito de toda a complexidade que constitui as dinâmicas interculturais contemporâneas que, inevitavelmente, impactam a existência dos povos indígenas.

Importante para os argumentos aqui apresentados é reconhecer que as bases epistemológicas que sustentam os principais campos de estudos dedicados às "línguas indígenas" no Brasil parecem compartilhar as mesmas ideologias desses discursos midiáticos no que diz respeito à autenticidade da identidade indígena e à desconsideração de dinâmicas de mobilidade intercultural, seja ela geográfica e/ou simbólica. Nesta direção, é possível compreender como as chamadas "línguas indígenas" têm sido objeto de análise sob duas principais perspectivas hegemônicas que compartilham a assunção da correlação inequívoca entre língua, cultura e território, e da fixidez, homogeneidade e estabilidade linguísticas. A primeira delas dedica-se à análise de características sistêmico-funcionais, sob diferentes abordagens teóricas e que tem como principais resultados descrições (não raro, chamadas de gramáticas) de partes de língua em suas dimensões fonético-fonológicas, morfossintáticas e, em menor escala, textuais ou discursivas. É, provavelmente, a perspectiva de maior impacto na produção acadêmica brasileira. ${ }^{6}$

\footnotetext{
${ }^{5}$ Cópia da reportagem disponível em: < https://pib.socioambiental.org/pt/noticias?id=118749>, acesso em dezembro de 2016.

${ }^{6}$ Como exemplo da produtividade deste campo de pesquisa, remeto o leitor e a leitora a um dos principais repositórios brasileiros de trabalhos sobre "línguas e culturas indígenas sul-americanas", a Biblioteca Digital Curt Nimuendajú,
} 
Outra perspectiva de grande produtividade e que se vincula às áreas de educação em língua materna e dos direitos linguísticos, enquadra-se nos limites de uma sociolinguística tradicional, que busca apresentar a situação das línguas indígenas em contínuos classificatórios, cujos polos mais radicais vão da vitalidade funcional às situações de risco de extinção e morte, tendo como principal critério de classificação o número de falantes que utilizam essas línguas (metodologia que se funda, também, em invenções como a delimitação fixa e estável, portanto enumerável, das línguas e de seus falantes).

Tarefa fundamental desta abordagem é, ainda, a compreensão dos fatores "externos" que expliquem as diferentes situações sociolinguísticas das comunidades indígenas que, no geral e apesar de toda a complexidade envolvida, desde esta perspectiva, compartilham o risco da perda ou substituição e do destino comum de serem vítimas da homogeneização sociocultural e linguística causada pelo contato, normalmente analisado desde categorias pautadas na ideologia do monolinguismo, aqui compreendida como um complexo de ideias, crenças e práticas por elas motivadas que assumem, como fundamento, "que as pessoas são intrinsecamente monolíngues, suas línguas são padrões (puros) e seus territórios limitados e sociolinguisticamente homogêneos" (BLOMMAERT, 2006, p. 518). Desde esta perspectiva, fluxos, hibridismos e a mobilidade de pessoas e de recursos comunicativos são descartados como situações excepcionais. A hegemonia desta ideologia no campo dos estudos da linguagem se justifica na medida em que o objeto privilegiado de análise continua sendo a língua, como entidade altamente abstrata, e não as práticas comunicativas reais de pessoas reais situadas num mundo real. É precisamente esta mudança de perspectiva que exige uma reconceitualização da ideia de língua de modo a abarcar o complexo conjunto de recursos comunicativos que as pessoas têm ao seu dispor para se comunicarem em seus cotidianos, como será abordado mais adiante neste trabalho.

Pouca atenção tem sido dispensada, assim, às diferentes formas de agência, apropriação e reelaboração de práticas comunicativas pelos povos e indivíduos indígenas no mundo globalizado do qual inevitavelmente fazem parte. Nesta direção, Blommaert (2010) destaca como discursos sobre direitos linguísticos (nos quais incluo, de maneira geral, os discursos epistemológicos que sustentam as políticas de educação em língua materna), perpetuam a tríade herderiana clássica território-cultura-língua e como, desde esta perspectiva, as funções das línguas são altamente territorializadas e estáticas e, alegadamente, prejudicadas tão logo o vínculo entre língua e localidade é desestabilizado. Assim, para o

disponível em: < http://www.etnolinguistica.org/index:projeto>, acesso em dez. de 2016. Inversamente, pelo mecanismo de busca da referida página, não há qualquer trabalho indexado sob palavras-chave como globalização, por exemplo. 
autor, programas que visam à promoção de "línguas maternas", normalmente "vincula[m] os falantes dessas línguas a um lugar e reforça[m] a conexão fixa presumida entre povo e ambiente - um claro reflexo da sincronia saussureana" (BLOMMAERT, 2010, p. 45).

Maher (2016), ao analisar criticamente o contexto indígena brasileiro posterior à promulgação da Constituição de 1988, que reconhece o direito das populações indígenas de usarem suas "línguas maternas" e adotarem processos próprios de ensino na educação escolar, constata que

\begin{abstract}
passou a ser legalmente permitido, e de certo modo encorajado o uso de suas línguas tradicionais. Mas observa-se que o que era uma permissão e incentivo, passou a ser entendido, também por muitos ativistas da causa indígena, como uma obrigatoriedade, principalmente entre muitos daqueles engajados na implementação de projetos de educação bilíngue nas aldeais. Assim, também os discursos próindígenas se mostraram circunscritos pela ideologia linguística dominante: se antes, para serem brasileiros legítimos todos os povos indígenas tinham que falar português, agora, para serem considerados índios legítimos eles teriam que falar língua indígena.[...] Era preciso garantir a continuidade do uso da língua ancestral ou a sua retomada, já que a perda da língua indígena passou a ser percebida como um impedimento, ou uma ameaça, à própria plataforma nacionalista indígena [...] (MAHER, 2016, p. 64)
\end{abstract}

Para Blommaert (2010), a relação unívoca entre identidade étnica, território e língua pode até ser aceitável, ao menos enquanto alguns aspectos da realidade forem convenientemente apagados, como a mobilidade, uma das dimensões mais incômodas às visões estabilizadoras e essencialistas de práticas comunicativas, uma vez que "nas estruturas sociais contemporâneas, a pessoas tendem a se mover, tanto no espaço geográfico, como no espaço simbólico" (BLOMMAERT, 2010, p.45). Esta mobilidade, contudo, é ainda periférica nas imaginações de língua hegemônicas do mundo ocidental e é ainda mais invisibilizada quando se refere às populações não urbanas situadas às margens do sistema mundo moderno/colonial, como são os povos indígenas, muito embora os efeitos da globalização e, consequentemente, dessa mobilidade, caracterize também essas populações.

Wang et al. (2014) entendem a globalização contemporânea como uma fase histórica particular, marcada pela interconectividade e pela mobilidade sem precedentes e que coincide com a expansão do capitalismo por todas as regiões do planeta. Conforme os autores, a globalização intensificou os fluxos globais e acrescentou uma camada hiperdinâmica de mobilidade de comunicação, de conhecimento e de informação aos níveis já aumentados de mobilidade física humana (WANG et al., 2014, p. 24). 
Muito embora os autores reconheçam um esforço recente nos estudos sociolinguísticos contemporâneos para a atualização de seu escopo teórico-analítico de forma a abordar a complexidade dos fenômenos comunicativos impulsionados pela mobilidade sem precedentes, Wang et al. são contundentes na crítica, segundo a qual, devido a um enviesamento teórico e, como eu argumento, geopolítico, localidades marginais e não urbanas, como "áreas periurbanas e rurais, áreas periféricas dos países, áreas periféricas do mundo, zonas institucionais periféricas onde minorias estão relegadas - têm sido menos rapidamente absorvidas nos estudos atuais" (WANG al., 2014, p. 26).

Para os autores, contudo, não há razão para excluir estas margens das análises das implicações sociolinguísticas dos processos de globalização, uma vez que "a globalização é uma transformação de todo o sistema mundo" e, portanto, "somos obrigados a enxergar os efeitos da globalização também em locais altamente inesperados” (WANG et al., 2014, p. 26). Ressaltam, ainda, que a principal condição para que os processos de globalização ocorram em qualquer lugar é a disponibilidade e a acessibilidade a sua infraestrutura, ou seja, aos instrumentos que possibilitam conexões entre eventos puramente locais e processos, padrões e desenvolvimentos translocais, de forma dialética e através de diferentes níveis escalares (WANG et al., 2014, p. 29). Dentre as formas de globalização implementadas nas margens, os autores destacam o acesso às novas tecnologias de mídia e comunicação, de especial interesse para este trabalho, como discutido na seção seguinte.

\section{Práticas comunicativas indígenas: plurilinguismos contemporâneos}

Jesus et al. (2014), ao analisarem a presença indígena no Facebook, inserem-na num contexto mais amplo da apropriação de infraestruturas de globalização pelos povos indígenas e constatam que a distância geográfica que separa suas comunidades dos grandes centros urbanos não os impede de se conectarem, mesmo que precariamente, ao universo virtual. Segundo os autores, o "rompimento dos limites geográficos é um forte elemento do contexto global, que não exclui as comunidades indígenas, para as quais não existem mais fronteiras geográficas à expressão do pensamento" (JESUS al., 2014, p. 10). Jesus et al. destacam como características mais salientes da autorrepresentação indígena nas redes sociais, a militância em prol dos direitos coletivos indígenas e usos linguísticos diferenciados na comunicação via internet, nos quais, aliados a recursos semióticos multimodais, elementos das línguas indígenas são usados juntamente com elementos da língua portuguesa (JESUS et al., 2014). 
Para a compreensão destas práticas contemporâneas, dois importantes movimentos teórico-analíticos são necessários: i) uma concepção de língua que abarque a mobilidade humana e semiótica, de modo a abranger todos "os recursos linguísticos reais empregados em contextos socioculturais, históricos e políticos reais" (BLOMMAERT, 2010, p. 5), empregados pelas pessoas em suas práticas comunicativas situadas; e ii) uma mudança de perspectiva em direção à interação comunicativa contextualizada, situada em tempos e espaços específicos.

Desde esta perspectiva, a noção de língua como objeto discreto, limitado e homogêneo dá lugar à compreensão mais ampla de repertórios comunicativos únicos (BLACKLEDGE \& CREESE, 2014; BLOMMAERT, 2010; GARCÍA \& WEI, 2014; JACQUEMET, 2016; JØRGENSEN, 2008, entre outros), porém complexos, dinâmicos e heterogêneos, constituídos, por sua vez, por recursos linguístico-discursivos, aqui compreendidos como "pedaços de línguas" que refletem todo o conhecimento de "sotaques, variedades linguísticas, registros, gêneros, modalidades tais como a escrita - formas de uso da língua em contextos comunicativos específicos e esferas de vida particulares, incluindo as ideias que as pessoas têm sobre essas formas de uso, suas ideologias linguísticas” (BLOMMAERT, 2010, p. 102).

A constituição destes repertórios comunicativos está, assim, intimamente relacionada às experiências de vida dos falantes, e se torna um dado biográfico, "uma estrutura que reflete nossas próprias histórias e aquelas das comunidades nas quais passamos nossas vidas" (BLOMMERT, 2010, p. 103). O vínculo com as trajetórias de vida, muitas vezes complexas, pode se refletir, inclusive, no que Blommaert (2010, p. 23) chama de um multilinguismo truncado, isto é, em "repertórios compostos de recursos especializados, mas parcialmente e desigualmente desenvolvidos", incluindo, assim, elementos tradicionalmente considerados pertencentes a línguas diferentes (JØRGENSEN, 2008, p. 168). Em tempos de acelerados processos de globalização, as situações de comunicação tecnologicamente mediadas e os recursos necessários a estas formas de interação passam também a compor os repertórios comunicativos dos falantes, incluindo daqueles situados às margens do mundo moderno/colonial.

Nesta direção, o uso de tecnologias desterritorializadas aliado aos usos de recursos semióticos híbridos para a comunicação constituem, basicamente, o que Jacquemet (2005) define como práticas transidiomáticas. O conceito, segundo o autor, visa descrever

práticas comunicativas de grupos transnacionais que interagem usando línguas e códigos comunicativos diferentes simultaneamente presentes em uma gama de canais comunicativos, tanto locais como distantes. Práticas transidiomáticas são os 
resultados da copresença de conversações multilíngues (exercida por falantes des/reterritorializados) e de mídias eletrônicas, em contextos altamente estruturados por indexicalidades sociais e códigos semióticos. Qualquer um presente em ambientes transnacionais, cuja conversação é mediada por tecnologias desterritorializadas e que interage com pessoas tanto presentes como distantes, se encontrará produzindo práticas transidiomáticas. (JACQUEMET, 2005, p. 264-265)

Para Jaquemet (2005, p.257) o conceito visa captar as "qualidades recombinantes da mistura, hibridização e crioulização linguísticas", através da reconceitualização do ambiente comunicativo, de modo a abordar práticas multilíngues, mediadas por meios eletrônicos e por recursos semióticos diversos com abrangência local e global e superar perspectivas teóricoanalíticas que têm como foco apenas as interações comunicativas locais face a face que, segundo o autor, são fortemente influenciadas por concepções modernas de língua, pois, da forma como "inventadas", concebem as comunidades de fala como entidades isoladas e homogêneas nos limites dos Estados-nação e analisam seus padrões de comunicação também com base num objeto claramente identificável e limitado: "a língua nacional, dominante, padronizada" (JACQUEMET, 2005, p.260).

Jacquemet enfatiza que essa concepção tem seu foco no hábito, ou seja, as práticas se tornam transidiomáticas quando os participantes utilizam habitualmente todos os recursos linguísticos e midiáticos disponíveis para expandirem suas interações sociais cotidianas, produzindo "um estilo comunicativo massivamente fluido, em camadas, baseado no acesso a múltiplos canais comunicativos para adquirir sua forma" (JACQUEMET, 2016a, p.342).

Considerando os elementos básicos da concepção proposta por Jacquemet, as instâncias comunicativas apresentadas a seguir ilustram a performance de práticas transidiomáticas por indivíduos indígenas e refletem, em diferentes níveis, a mobilidade que caracteriza suas trajetórias de vida, assim como a de muitos outros indivíduos indígenas na contemporaneidade.

P. krikati $^{7}$ é um jovem originário de uma aldeia do povo Krikati, situada no sudoeste do estado do Maranhão. Em 2014, o jovem indígena foi aprovado no vestibular para o curso de Licenciatura em Educação Intercultural, na Universidade Federal de Goiás, na cidade de Goiânia. Esta trajetória já apresenta dimensões importantes da mobilidade na qual se insere esse jovem, tanto geográfica como epistemológica, uma vez que requer o deslocamento de quem foi criado numa aldeia para uma capital brasileira e onde, inequivocamente, dado o contexto acadêmico do qual passou a fazer parte, colocou em contato os conhecimentos particulares de seu povo com os conhecimentos de outras matrizes culturais e geopolíticas.

\footnotetext{
${ }^{7}$ Utilizo aqui iniciais maiúsculas para etnônimos comumente usados nos sobrenomes indígenas e para a definição do povo. Iniciais minúsculas são usadas na referência às línguas indígenas.
} 
Suas práticas comunicativas também refletem essa mobilidade, uma vez que, o contato com recursos linguísticos e semióticos diferentes se amplia em intensidade e escopo e, com maior frequência, são mediadas por tecnologias de comunicação, como ilustra a Figura $1^{8}$ a seguir, que reproduz uma interação com um colega universitário, também do povo Krikati, através do aplicativo de mensagens WhatsApp, instalado em seu telefone celular.

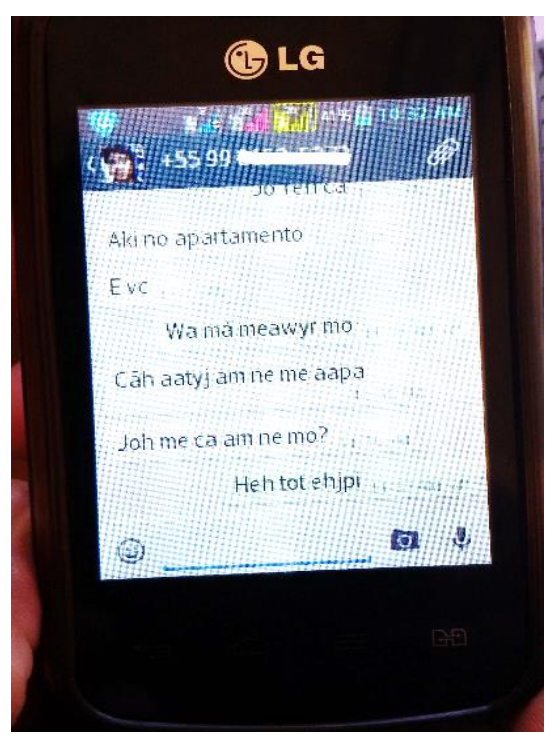

Figura 1 - Prática transidiomática via WhatsApp - Foto: André M. Nascimento, em agosto de 2014

Como destaca Jacquemet (2016b, 21), as tecnologias digitais de comunicação alteram a própria natureza da interatividade, confrontando os usuários com regras e recursos expandidos para construção de identidades sociais, transformando seu senso de lugar, pertencimento cultural e as próprias relações sociais, e ainda ocupando um espaço na experiência cotidiana distinto das interações que se constituem com a proximidade física. Neste sentido, destacam-se na interação reproduzida na Figura 1 acima alguns elementos importantes para a compreensão de formas contemporâneas de comunicação indígena. $\mathrm{O}$ primeiro deles é o uso híbrido de recursos linguísticos normalmente atribuídos a diferentes línguas, mas que, desde a concepção teórica aqui adotada, são melhor vistos como constituintes de repertórios complexos.

$\mathrm{Na}$ situação, os estudantes indígenas utilizam seus repertórios comunicativos heterogêneos e misturam recursos do que normalmente chamamos de português com recursos da chamada língua krikati. Os recursos do português, por sua vez, indiciam duas importantes dimensões sociais da interação, a da localização dos estudantes no espaço urbano, como em

\footnotetext{
${ }^{8} \mathrm{O}$ uso das imagens captadas por foto e captura de tela foi previamente autorizado pelos estudantes indígenas.
} 
"Aki no apartamento"; e a da apropriação de recursos de letramento característicos da comunicação escrita digitalmente mediada, como em "Aki" e " $v c$ ". De maneira geral, o uso desses recursos indicia como novos textos, contextos e mensagens têm sido apropriados e produzidos por indivíduos indígenas na contemporaneidade intercultural em que atuam e como, desde estes espaços, emergem-se afiliações e autorrepresentações identitárias recombinantes. Da mesma forma, conforme Blommaert (2010, p. 64), é importante perceber como a vernacularização da globalização através do uso de recursos das línguas indígenas em canais digitalmente mediados pode revelar a potencialidade de esses recursos mostrarem-se plenamente aptos à produção globalizada de sentidos e de disseminação de novas formas de letramento e de modelos de mensagens.

P. Krikati é também usuário da rede social Facebook, onde se apresenta como "Indígena com orgulho, ama sua cultura, festas tradicionais, adora animes, séries e filmes", o que reafirma traços de suas múltiplas afiliações identitárias e culturais. Suas postagens nessa rede social são performadas prioritariamente com recursos do português, muito embora esses recursos, aliados a uma quantidade massiva de recursos audiovisuais, sirvam, frequentemente, à militância em prol das causas indígenas e da valorização de aspectos das culturas indígenas brasileiras.

Naturalmente, a rede social serve também ao jovem indígena como um meio de expressar reflexões e acontecimentos cotidianos de sua vida. Na Figura 2, por exemplo, P. krikati faz uso do Facebook para informar aos integrantes de sua rede sua aprovação, em 2015, para o curso de Ciências Biológicas, na universidade onde já era estudante. Ao lado de uma fotografia que o posiciona no contexto urbano da universidade, o estudante utiliza recursos do português para a comunicação num ambiente marcado pela multiculturalidade, já que são constituintes de sua rede pessoas de diferentes procedências, nelas incluídas indígenas de diferentes povos e não indígenas. Em alinhamento com o ambiente comunicativo, P. Krikati utiliza ainda recursos característicos da escrita multimodal digital, como as hashtags que dão ênfase a tópicos importantes de sua mensagem, como "\#Ciênicias \#Biológicas aí vou $e u$ " (sic). Como característico da interação nas redes sociais, a postagem do estudante indígena foi altamente repercutida por seus amigos virtuais através de curtidas e comentários, a maior parte deles escritos por seus, a partir de então, ex-colegas indígenas do curso de Educação Intercultural. Um desses comentários, reproduzido na Figura 3, é de particular interesse para as reflexões aqui apresentadas. 


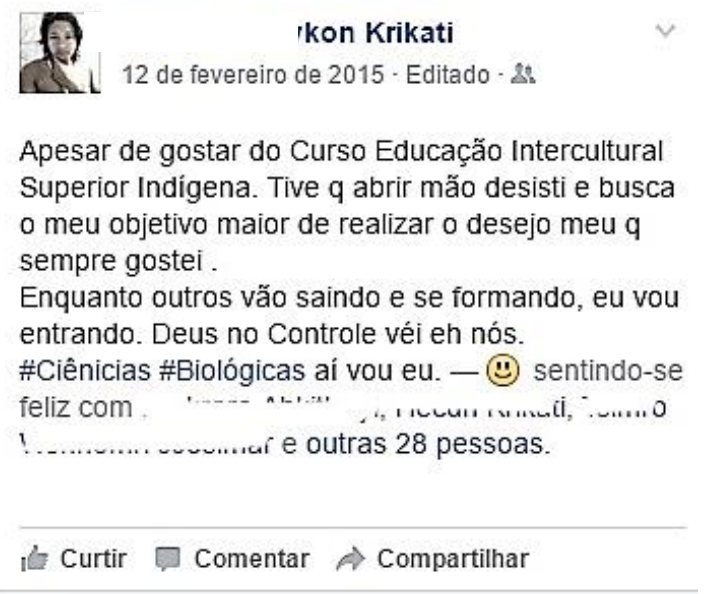

Figura 2 - Postagem na rede social Facebook - Captura de tela em janeiro de 2017

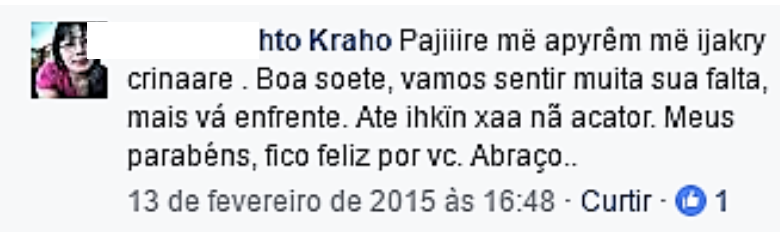

Figura 3 - Comentário transidiomático - Captura de tela em janeiro de 2017

No comentário, a estudante indígena do povo Krahô parabeniza e deseja boa sorte para seu ex-colega de curso e, para isso, utiliza recursos linguísticos da língua krahô e da língua portuguesa, de forma híbrida e justaposta no mesmo enunciado. Para uma compreensão mais aprofundada desta interação transidiomática, faz-se importante compreender que os povos indígenas Krikati e Krahô utilizam recursos linguísticos parcialmente convergentes, ou seja, possuem repertórios linguísticos que compartilham muitos recursos comuns, apesar de não serem plenamente idênticos, o que possibilita a intercompreensão na comunicação intercultural. O conhecimento desta convergência de recursos, que também compõe os repertórios comunicativos dos dois jovens indígenas, é o que garante que a mensagem faça sentido entre os interlocutores. A estudante krahô explica que os recursos do português foram utilizados precisamente para suprir lacunas para as quais não haveria convergência entre os repertórios indígenas. ${ }^{9}$ Desde a interpretação aqui proposta, percebe-se como a interação e a produção de sentidos é possibilitada pelos recursos linguísticos-discursivos heterogêneos compartilhados, neles incluídos os conhecimentos comum de recursos das línguas indígenas, da língua portuguesa e de recursos multimodais comuns à interação via rede social.

\footnotetext{
${ }^{9}$ Comunicação pessoal ao autor, em janeiro de 2016.
} 
Além de se configurar como uma autêntica prática transidiomática, o comentário da estudante krahô serve ainda como uma interessante evidência da imprecisão na delimitação fixa das fronteiras entre línguas diferentes tendo a identidade étnica como parâmetro. A comunicação entre os estudantes indígenas de povos diferentes é possibilitada, precisamente, pela porosidade e pela instabilidade de suas bordas, apesar de a classificação etnolinguística ocidental categorizá-las como línguas diferentes (cf. RODRIGUES, 2013, entre outros), perspectiva sob a qual a única aproximação possível entre essas línguas e povos se dá em supracategorias teóricas, não menos estanques, como famílias e troncos. As línguas são, assim, classificadas e agrupadas, conforme esclarece Rodrigues, de acordo com critérios genéticos e hipóteses de uma língua ancestral comum, conforme o nível de "afinidade em sua gramática e em seu léxico" (RODRIGUES, 2013, p. 11). ${ }^{10}$

Desde a perspectiva da invenção das línguas, Makoni e Mashiri (2007) enfatizam como tais classificações são, na verdade, resultados de "ficções linguísticas" que não representam línguas reais e como em nada contribuem para a compreensão e para a melhoria da natureza da comunicação entre as pessoas. Se esta deve ser a agenda dos estudos da linguagem na contemporaneidade globalizada, importa mais reconhecer, conforme Jacquemet (2016, p.335-336), que nestes novos e complexos cenários comunicativos “o que conta não é que 'língua' se fala, mas a capacidade de se fazer compreendido pelos outros (baseado em formas semióticas translinguísticas) e ser visto como um ser social normal”. No caso de indivíduos e povos indígenas, o posicionamento e a compreensão teórico-analítica de suas práticas comunicativas na contemporaneidade parece ser tarefa ainda mais complexa, pois, conforme constata Maher, no imaginário não indígena, os indígenas ocupam tempo e espaço predeterminados e deles se espera performances comunicativas não menos predeterminadas, apesar de não termos qualquer dificuldade em aceitar o dinamismo de outras identidades

\footnotetext{
${ }^{10}$ É importante, neste ponto, salientar que, ao problematizar as rígidas fronteiras definidoras de línguas e de identidades etnolinguísticas, não é meu intuito propor que as línguas indígenas sejam consideradas uma mesma língua, dada, neste caso especifico, a possibilidade de intercompreensão entre os estudantes indígenas, fenômeno explicado pela etnolinguística ocidental pela relação de "parentesco" entre as línguas krikati e krahô. A mudança de perspectiva é mais profunda e, de muitas formas, epistemológica. Como mencionado, me alinho a propostas que mudam o foco do estudo da língua, como entidade abstrata, homogênea, estável e limitada, para a compreensão de situações comunicativas reais. Em coerência com este posicionamento, os objetos privilegiados seriam em si a interação comunicativa contextualizada e os recursos comunicativos empregados para a produção de sentido entre os interlocutores que, de muitas formas, extrapolam as imaginações hegemônicas e modernas de língua. Em contextos mais salientes de interações comunicativas de sala de aula no curso de Licenciatura em Educação Intercultural, em diversos momentos, pude perceber, por exemplo, interações entre estudantes considerados pertencentes a famílias linguísticas radicalmente diferentes em que o uso de recursos heterogêneos (i.e. pertencentes às diferentes línguas em jogo) foram acionados e fizeram sentido na comunicação. Situações como estas sugerem que o foco em línguas como entidades abstratas, homogêneas e discretas se mostra insuficiente para a compreensão deste tipo de situação, melhor compreendida desde uma perspectiva de repertórios complexos constituídos pelas/nas trajetórias de vidas dos estudantes, marcadas, neste caso, pelo contato intenso com outros grupos culturais.
} 
culturais. Para a autora, "no que tange aos povos indígenas a tendência é coloca-los como reféns do que seriam seus costumes ancestrais" (MAHER, 2016, p. 62).

Esta essencialização estratégica da identidade indígena, como busco argumentar, ultrapassa os limites do imaginário nacional e se configura como pressuposto epistemológico nos estudos da linguagem hegemônicos, mesmo em perspectivas mais críticas e voltadas para o que as pessoas fazem, de fato, com seus repertórios comunicativos.

Neste sentido, apesar de a concepção de prática transidiomática ser útil para a compreensão das práticas comunicativas exemplificadas nesta seção, compreendo como necessária a crítica no que se refere ao seu escopo de aplicação que, em algum sentido, não abarca as interações comunicativas de populações indígenas de territórios pós-coloniais. Isto ocorre, basicamente, porque Jacquemet (2005, 2016a, especialmente) ao fundar sua definição de práticas transidiomáticas nas interações de grupos transnacionais em mobilidade, principalmente em situações de migrações internacionais, mantém a ideia de nacionalidade, portanto de nação, em seu centro. Desde a perspectiva teórica aqui adotada, (como brevemente apontado em LUCENA \& NASCIMENTO, 2016), é preciso reconhecer três pontos problemáticos: i) os Estados-nação como entidades também inventadas como parte da construção da modernidade; ii) a negligência à complexidade interna constituinte do que viria a se tornar as nações modernas e as nações surgidas dos processos prévios de colonização; e iii) o reconhecimento de que uma das principais estratégias para a constituição ideológica, geográfica e humana das nações, com território, língua e cultura imaginados como homogêneos, foi a invisibilização histórica dos grupos racialmente inferiorizados, como são os povos indígenas no Brasil, através de seu extermínio físico e/ou simbólico.

Para incluir as dinâmicas culturais e sociolinguísticas indígenas na contemporaneidade, torna-se, assim, necessária a ampliação conceitual da ideia de prática transidiomática, de modo a considerar os efeitos do colonialismo interno, definido por Mignolo (2011, p. 135136), como as consequências da instituição de uma matriz colonial de poder que, mesmo após a descolonização de territórios, manteve as mesmas estruturas de controle e administração instituídas no período inicial de colonização europeia, nas quais a racialização hierárquica mantém-se como um dos pilares principais. Em outras palavras, proponho que o escopo do conceito de práticas transidiomáticas inclua a sempre existente diversidade interna dentro dos limites dos Estados-nação e não restrinja seu foco a apenas fluxos transnacionais. Esse reconhecimento põe em relevo, por sua vez, ao menos duas dimensões importantes: i) mesmo tendo vivenciado violentamente todas as consequências da colonização, os povos indígenas se reconfiguram cultural e politicamente como forma de resistência contemporânea, nela 
incluída a complexa e estratégica dinâmica entre essencialismos e afiliações identitárias fluídas; e ii) para que sua contemporaneidade não continue sendo negada, suas experiências e trajetórias de vida, nelas incluídas suas práticas comunicativas e suas epistemologias, devem ser consideradas de modo a descentralizar a produção hegemônica de conhecimento.

\section{Considerações finais}

Muito embora o pensamento sociolinguístico crítico contemporâneo contribua para uma compreensão mais ampla das diferentes situações comunicativas no mundo globalizado, como é o caso da noção de práticas transidiomáticas acima abordada, creio que uma verdadeira descentralização epistemológica no campo dos estudos da linguagem só encontrará vias para sua concretização através da validação de outras experiências geo e corpo-políticas, alternativas ao conhecimento de matriz ocidental, mas delas não independentes.

Assim, para finalizar as reflexões aqui propostas, apresento uma possibilidade teóricoanalítica elaborada desde o que aqui venho chamando de margens do sistema mundo moderno/colonial, compreendidas como espaços não apenas geográficos, mas que implicam “a existência de povos, línguas, religiões e conhecimentos de dois lados ligados pelas relações estabelecidas pela colonialidade do poder (i.e. estruturadas pelas diferenças imperiais e coloniais) $"$ (MIGNOLO, 2012, p. 62).

Mutua Mehinaku, desde seu lócus situado de enunciação, ou seja, de um indígena xinguano que carrega em seu corpo as marcas do hibridismo cultural e linguístico, apresenta a interessante categoria de pensamento indígena “Tetsualü”, assim descrita por ele:

A palavra Kuikuro tetsualü pode ser traduzida por 'misturado', como uma mistura de cores no colorido de alguma coisa, uma mistura de comida diferentes uma mistura de tamanhos diferentes [...]. Tetsualü é também uma mistura de línguas e dialetos na fala, uma mistura de etnias na história de vida de uma pessoa. Este trabalho gira em torno da ideia de tetsualü quando se fala de pessoas e de línguas. $\mathrm{O}$ Alto Xingu é tetsualü; a aldeia de Ipatse é tetsualü; eu sou tetsualü (MUTUA MEHINAKU, 2010, p. 01). ${ }^{11}$

O intelectual indígena nos fornece, assim, uma categoria pensada desde outro lugar geopolítico, desde a experiência de outros corpos, situados precisamente nas fronteiras internas

\footnotetext{
${ }^{11} \mathrm{O}$ conceito "tetsualü", aqui breve e superficialmente abordado, se apresenta como uma categoria de pensamento indígena com fecundo potencial para análise de dinâmicas interculturais contemporâneas e de suas inequívocas dimensões comunicativas. Contudo, pelos limites e objetivos deste trabalho, não foi ainda utilizado como categoria interpretativa plena, mas apenas (e por enquanto) como uma alternativa possível às imaginações ocidentais de linguagem e como prova incontestável da contemporaneidade epistemológica indígena, situada, por sua vez, em outro posicionamento geopolítico. Sua implementação como categoria teórico-analítica tem feito parte das reflexões desenvolvidas no âmbito do projeto de pesquisa do qual resulta este trabalho que, por seus limites, impediram aqui seu aprofundamento.
} 
do Estado-nação, ou seja, desde a experiência daqueles que foram invisibilizados para que o ideal de nação pudesse se concretizar. E nos mostra como práticas contemporâneas de linguagem marcadas pela globalização também podem ser compreendidas desde perspectivas indígenas, já que em sua análise utiliza a concepção de tetsualü para abarcar a experiência indígena de apropriação "do mundo da tecnologia e da "ciência dos Brancos" e de seus "aki humini (enviador de palavras)" (MEHINAKU, 2010, p. 182), condição inequívoca para a concretização do que Jacquemet chama de práticas transidiomáticas.

Assim, me parece absolutamente válido compreender as práticas comunicativas aqui analisadas como autênticas práticas tetsualü, especialmente por essa concepção se apresentar como alternativa viável aos limites internos e, principalmente, aos limites externos da imaginação hegemônica de língua no mundo ocidental.

\section{REFERÊNCIAS}

BARROS, Maria Cândida Drummond Mendes. Educação bilíngue, linguística e missionários. Em Aberto, Brasília, a. 14, n. 63, 1994, p. 18-37.

BARROS, Maria Cândida Drummond Mendes. A missão Summer Institute of Linguistics e o indigenismo latino-americano: história de uma aliança (décadas de 1930 a 1970). Revista de Antropologia, v. 47, n. 1, 2004, p. 45-85.

BLACKLEDGE, Adrian; CREESE, Angela. Heteroglossia as practice and pedagogy. In:

BLACKLEDGE, Adrian; CREESE, Angela (eds.). Heteroglossia as practice and pedagogy. New York: Springer, 2014, p. 1-20.

BLOMMAERT, Jan. Language ideology. In: BROWN, Keith (ed.). Encyclopedia of Language \& Linguistics, $2^{\text {nd }}$ ed., v. 6. Oxford: Elsevier, 2006, p. 510-522.

BLOMMAERT, Jan. The Sociolinguistics of Globalization. Cambridge: Cambridge University Press, 2010.

GARCÍA, Ofelia; WEI, Li. Translanguaging: Language, Bilingualism and Education. New York: Palgrave Macmillan, 2014.

JACQUEMET, Marco. Transidiomatic practices : language and power in the age of globalization. Language and communication, n. 25, 2005, p. 257-277.

JACQUEMET, Marco. Language in the Age of Globalization. In : BONVILLAIN, N. (ed.). The Routledge Handbook of Linguistic Anthropology. New York : Routledge, 2016a, p. 329347.

JACQUEMET, Marco. Transidioma. Revista da Anpoll, n. 40, 2016b, p. 19-32.

JESUS, Naine Terena et al. Presença indígena no Facebook e a construção de narrativas. Fronteiras e Debates, v. 1, n. 2, 2014, p. 9-28.

JØRGENSEN, Jens Normann. Polylingual languaging around and among children and adolescentes. International Journal of Multilingualism. v. 5, n. 3, 2008, p. 161-176.

LUCENA, Maria Inêz Probst; NASCIMENTO, André Marques. Práticas (Trans)

Comunicativas Contemporâneas: Uma Discussão Sobre Dois Conceitos Fundamentais. Revista da Anpoll, n. 40, Jan/Jul. 2016, p. 46-57. 
MAHER, Terezinha M. Sendo índio na cidade: mobilidade, repertório linguístico e tecnologias. Revista da Anpoll, n. 40, 2016, p. 58-59.

MAKONI, Sinfree; PENNYCOOK, Alastair. Disinventing and reconstituting languages. In: (eds.). Disinventing and reconstituting languages. Clevedon/Buffalo/Toronto:

Multilingual Matters, 2007, p. 1-41.

MAKONI, Sinfree; MASHIRI, Pedzisai. Critical historiography: Does language planning in Africa need a constructo of language as parto $\mathrm{f}$ its theoretical apparatus? In: MAKONI, Sinfree; PENNYCOOK, Alastair. (eds.). Disinventing and reconstituting languages. Clevedon/Buffalo/Toronto: Multilingual Matters, 2007, p. 62-89.

MEHINAKU, Mutua. TETSUALÜ : pluralismo de línguas e pessoas no Alto Xingu. Dissertação (Mestrado em Antropologia Social) - Programa de Pós-graduação em Antropologia Social/Museu Nacional. Rio de Janeiro: Universidade Federal do Rio de Janeiro, 2010.

MIGNOLO, Walter D. Desobediencia epistémica: retórica de la modernidad, lógica de la colonialidad y gramática de la descolonialidad. Buenos Aires: Ediciones del signo, 2010. MIGNOLO, Walter D. The darker side of Western modernity: global futures, decolonial options. Durham/London: Duke University Press, 2011.

MIGNOLO, Walter D. Theorizing from the borders: shifting to the geo- and body- politics of Knowledge. In: TLOSTANOVA, Madina V.; MIGNOLO, Walter D. Learning to unlearn: decolonial reflections from Eurasia and the Americas. Columbus: The Ohio State University Press, 2012, p. 60-79.

PENNYCOOK, Alastair. The myth of English as an international language. In: MAKONI, Sinfree; PENNYCOOK, Alastair. (eds.). Disinventing and reconstituting languages. Clevedon/Buffalo/Toronto: Multilingual Matters, 2007, p. 90-115.

RODRIGUES, Aryon Dall'Igna. Línguas indígenas brasileiras. Brasília, DF: Laboratório de Línguas Indígenas da UnB, 2013. 29p. Disponível em: <http://www.laliunb.com.br>. Acesso em: janeiro de 2017.

SOUZA, Lynn Mario T. Menezes de. Entering a culture quietly: writing and cultural survival in indigenous education in Brazil. In: MAKONI, Sinfree; PENNYCOOK, Alastair (ed.).

Disinventing and reconstituting languages. Clevedon: Multilingual Matters, 2007. p. 135-169. VIVEIROS DE CASTRO, Eduardo. Prefácio: O recado da mata. In: KOPENAWA, Davi; ALBERT, Bruce. A queda do céu: palavras de um xamã yanomami. Tradução de Beatriz Perrone-Moisés. São Paulo: Cia das letras, 2015, p. 11-41.

WANG, Xuan et al. Globalization in the margins: toward a reevolution of language and mobility. Applied Linguistics Review, v. 5, n.1, 2014. p. 23-44. 